\title{
Kernos
}

Revue internationale et pluridisciplinaire de religion grecque antique

$20 \mid 2007$

Varia

\section{MORTIER-WALDSCHMIDT Odile (éd.), Musique \& Antiquité. Actes du colloque d'Amiens, 25-26 octobre 2004}

André Motte

\section{OpenEdition}

\section{Journals}

Édition électronique

URL : https://journals.openedition.org/kernos/400

DOI : $10.4000 /$ kernos.400

ISSN : 2034-7871

\section{Éditeur}

Centre international d'étude de la religion grecque antique

\section{Édition imprimée}

Date de publication : 1 janvier 2007

Pagination : 453-454

ISSN : 0776-3824

\section{Référence électronique}

André Motte, « MORTIER-Waldschmidt Odile (éd.), Musique \& Antiquité. Actes du colloque d'Amiens, 25-26 octobre 2004 », Kernos [En ligne], 20 | 2007, mis en ligne le 17 mars 2011, consulté le 08 septembre 2022. URL : http://journals.openedition.org/kernos/400 ; DOI : https://doi.org/10.4000/kernos.400 
Si la majeure partie de cet ouvrage se présente comme un rapport de fouille classique offrant un catalogue minutieux des objets mis au jour, la partie IV propose davantage une réflexion sur les cultes et les rites pratiqués dans cet espace sacré. On retiendra notamment une discussion sur l'identification des domaines d'intervention de la divinité à partir de l'iconographie votive; les actes rituels comme le sacrifice, la libation ou le repas; l'importance de l'eau dans la dynamique du sacré ou encore l'existence supposée d'un culte des dieux Lares à Satriano. Ce bel ouvrage auquel ont participé pas moins de vingt-huit auteurs est documenté par de nombreux dessins, cartes, relevés, graphiques et clichés noir et blanc et couleur de très bonne qualité. On ne peut que saluer le zèle et le soin avec lesquels les éditeurs ont publié les résultats de ces fouilles venant ainsi compléter la documentation archéologique et religieuse des sanctuaires de Basilicate.

Sandrine DUCATÉ-PAARMANN (Université de Fribourg, $\mathrm{CH}$ )

Mortier-Waldschmidt Odile (éd.), Musique \& Antiquité. Actes du colloque d'Amiens, 25-26 octobre 2004, Paris, Les Belles Lettres, 2006. 1 vol. 13,5 × $21 \mathrm{~cm}$, 314 p. ISBN : 2-251-44303-7.

Il apparaît qu'après un temps d'éclipse les études portant sur la musique de la Grèce ancienne retrouvent quelque faveur. Témoins le colloque Chanter les dieux. Musique et religion dans l'Antiquité grecque et romaine qui s'est tenu à Rennes en 1999, les Actes ayant paru deux ans plus tard, et le présent ouvrage qui, issu lui aussi d'une rencontre scientifique, répartit les 14 communications présentées, sans compter une introduction de J. Lacarrière sur «La musique grecque d'hier à aujourd'hui », en quatre thématiques : "De la musique en littérature », «De la musique en philosophie », «Des musiciens » et «Échos modernes ». Cette fois, la religion n'est donc plus à l'honneur, ce qui se comprend bien. Néanmoins, une contribution due à Danièle Aubriot, qui la dédie à la mémoire de Jean Rudhardt, concerne directement le domaine: «De la lyre à l'arc. Fonctions religieuses de la musique chez Homère. » Cette fine étude d'une homérologue avertie, et très versée aussi, comme on sait, dans les recherches religieuses, ne manquera pas d'intéresser et peut-être aussi de surprendre. Que la musique, en effet, soit pour ce poète un moyen essentiel de susciter la présence du divin et de communiquer avec lui, d'être à ce titre un gage de concorde parmi les hommes, l'harmonie musicale s'avérant de surcroît liée à l'harmonie du monde, ne saute pas aux yeux. Ces denses conclusions découlent d'une analyse minutieuse des passages successifs de l'Iliade et l'Odyssée qui évoquent des scènes de musique, au total une bonne dizaine. Qu'on se rappelle, par exemple, dès le livre I du premier poème, la scène montrant les guerriers Achéens venus chanter et danser en l'honneur d'Apollon dans un but de propitiation et de réconciliation (v. 472-474) ou, au même chant, le concert qui, dans l'Olympe, au terme d'un banquet, consacre la bonne entente retrouvée parmi les dieux eux-mêmes (v. 603-604), ou encore les trois vignettes musicales du bouclier d'Achille (XVIII, 495, 569-572, 604-605) dont la dernière fait voir un chœur opérant des révolutions qui font écho à celle des corps célestes. Quant à l'Odyssée, elle illustre bien, à la faveur des chants de Démodocos (VIII, 62 sq.), le souci qu'a le roi Alkinoos de réunir, grâce à la musique, les inviteurs et l'invité dans la joie et la concorde. Mais, ne manquera-t-on pas d'objecter, où est ici la fonction religieuse de la musique ? Et si l'on se réfère à d'autres passages du poème (I, 150 sq., 325-355), n'y voit-on pas que la musique y est présentée comme un pur et simple divertissement dont se délectent les prétendants ? Assurément, reconnaît l'A. dans un habile et efficace plaidoyer, mais c'est cela précisément qu'Homère dénonce tout au long. Les scènes en question montrent a contrario que pareil usage de la musique dénature celle-ci et que cette grave faute est celle de gens qui mènent une vie scandaleuse, à l'écart des dieux. 
Aussi bien l'arc d'Ulysse, dont le poète note explicitement qu'il «fait entendre un beau chant» (XXI, 404-411), symbolise-t-il l'ordre que restitue la vengeance du héros, celui des liens sociaux authentiques et aussi des obligations cultuelles qui sont dues au dieu Apollon le jour de sa fête, superbement ignorée par les prétendants. La démonstration est remarquable et très convaincante. Elle l'est un peu moins peut-être lorsque, dans l'Iliade déjà, un argument similaire est utilisé à propos du jeu musical dans lequel Achille est dit se complaire lorsqu'il reçoit la visite des ambassadeurs achéens. Il y aurait, ici aussi, dénonciation d'une carence de la musique pratiquée, mais c'est moins évident. Il reste que les poèmes homériques, comme le montre bien cette étude, affirment nettement la fonction sociale et religieuse de la musique.

On trouvera assurément plaisir aussi dans la lecture des autres pages de ce volume dont un article encore traite d'un thème qui n'est pas sans rapport, quoique indirectement cette fois, avec la religion : C. Calame, "Jeux de genre et performance musicale dans le chœur de la tragédie classique : espace dramatique, espace cultuel, espace civique ».

A. Motte

(Université de Liège)

RUDHARDT Jean, Les dieux, le féminin, le pouvoir. Enquêtes d'un historien des religions, édité par Philippe Borgeaud et Vinciane Pirenne-Delforge, Genève, Labor et Fides, 2006. 180 p. ISBN : 2-8309-1219-5.

Tous ceux qui connaissent l'œuvre du regretté Jean Rudhardt et qui apprécient en particulier sa très précieuse contribution à l'étude de la religion grecque se réjouiront de la parution de cet ouvrage posthume qui publie le texte de sept conférences inédites, échelonnées de 1956 à 1998 et comprenant chacune une vingtaine de pages. Dans la préface, Ph. B. esquisse quelques aspects du cheminement intellectuel et de la démarche méthodologique de celui qui fut son maitre tandis que V.P., prenant le relais, s'emploie à situer la conception originale du mythe dont J.R. s'est fait le défenseur.

Si les textes ici rassemblées n'étaient pas destinés à former un livre et abordent des sujets très variés dont le titre choisi ne donne qu'une idée approximative, ils n'en reflètent pas moins une unité de pensée et de méthode. C’est ainsi que les trois premières conférences mettent les thématiques abordées en rapport avec les données sociales et politiques qui sous-tendent les mythes concernés. - La première, intitulée «Puissance et souveraineté selon l'enseignement de quelques mythes grecs », entend montrer comment ces récits peuvent nous renseigner sur la manière dont les Grecs concevaient le pouvoir politique. Elle propose tout d'abord une paraphrase explicative de la Théogonie d'Hésiode, dont l'histoire, à ses débuts, illustre les conditions nécessaires à l'établissement du pouvoir et à son exercice, puis, à l'avènement de Zeus, ce que requierent l'équilibre et la permanence de son règne. Il est montré ensuite comment les mythes hérö̈ques impliquent des formes nouvelles de légitimité. Pleine de fines observations souvent inattendues, cette étude insiste à la fin sur l'idée que «la vérité d'un mythe ne réside pas dans la réalité des événements qu'il raconte mais dans ce qu'au-delà d'eux ces événements signifient». - C'est à faire voir certains "Reflets de la féminité dans le miroir de la mythologie grecque » que s'attache la $2^{\mathrm{e}}$ contribution, la plus longue de toutes $(33$ p.). Elle commence par un judicieux rappel. Les mythes anciens que conservent les cultures européennes ayant été vidés de leur sens religieux, nous en avons oublié le sens profond et nous avons quelque peine à réaliser qu'ils visent à «éclairer la situation de l'homme face au monde, dans son rapport à la réalité divine ». Le présent exposé tend à montrer comment les principales déesses du panthéon s'insèrent dans le système ainsi conçu, à commencer par la déesse Gaia, pièce maitresse de la cosmogonie qui est au centre de ce système. L'A. rectifie au passage certaines idées reçues : il montre, par 